\title{
Study of prediction of hypotension at induction of general anesthesia by internal jugular vein measured by ultrasonography
}

K. OKAMURA ${ }^{1}$, T. Nomura², T. Goto ${ }^{2}$

1) Yokohama City University Hospital - Yokohama (Japan) $\quad$ 2) Yokohama City University - Yokohama (Japan)

\section{Background and Goal of Study}

It has been reported that preoperative ultrasonographic inferior vena cava evaluation to assess the intravascular volume could be useful as a predictor of hypotension during the induction of general anesthesia.

However, no report can be found about pre-anesthetic internal jugular vein (IJV) evaluation even though it can be performed easily and quickly.

The estimation of fluid responsiveness during shock patients has also been assessed using passive leg raising test.

Therefore, this study has been conducted to clarify whether ultrasonographic IJV evaluation with supine (Su) and/or Trendelenburg (Tr) position just before anesthesia induction can be a predictor of hypotension caused by the anesthetic administration.

Adult patients scheduled for surgeries under general anesthesia

\section{Materials}

$>$ Exclusion criteria: emergency surgery, history of heart failure, moderate or severe valvular disease, aortic disease, peripheral artery disease, ejection fraction $<40 \%$, ASA-PS III or worse

Just before anesthesia induction

\section{Methods}

Blood pressure (BP) and heart rate (HR) were recorded (baseline).

Ultrasonographic IJV recording

Supine position
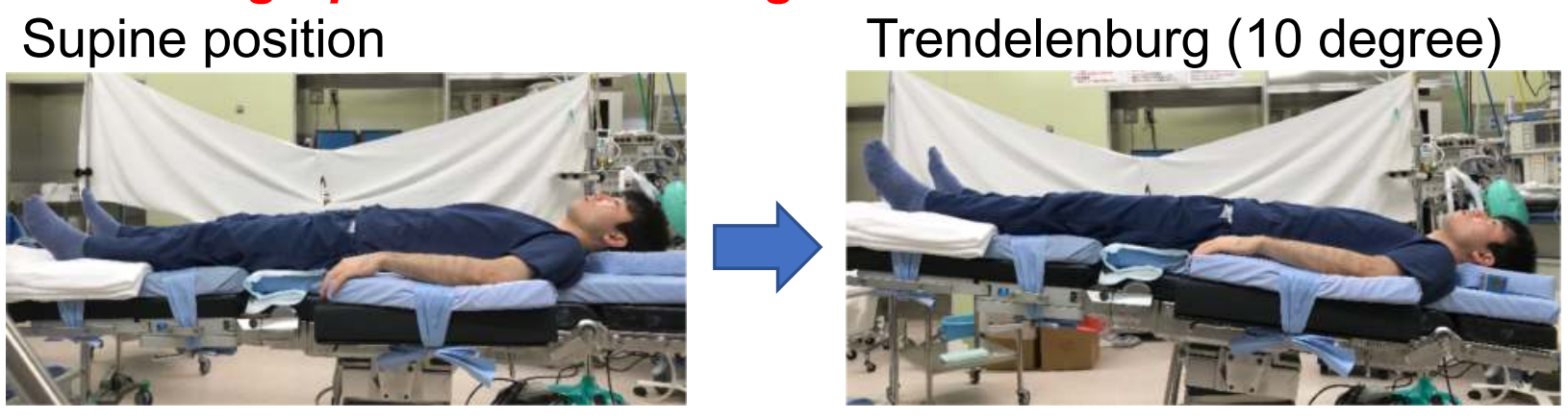

Off-line IJV Measurements

Anesthesia induction

General anesthesia was induced.

(fentanyl $3 \mathrm{mcg} / \mathrm{kg}$ propofol $1.5 \mathrm{mg} / \mathrm{kg}$ rocuronium $0.6 \mathrm{mg} / \mathrm{kg}$ )

After propofol administration (before tracheal intubation)

- BP is measured every minute for 5 minutes after propofol administration.

Hypotension during the induction was defined as mean-BP less than $60 \mathrm{mmHg}$ or greater than $30 \%$ decrease from baseline.

Statistical analysis

Patients' characteristic and measured values were analyzed by Man-Whitney $U$ test and receiver operating characteristic curve.

29 patients were studied.

Results

Hypotension after induction was observed in 12 patients.

Patients in hypotensive group were significantly older than these in non-hypotensive group. There was no significant difference in the other patient characteristics (hypertension, use of antihypertensive agents and/or diuretics, cerebrovascular disease, diabetes mellitus, renal dysfunction. There was also no significant difference in baseline BP and HR (table 1).

IJV areas at supine were $1.35(0.93-1.53)$ in hypotensive group and $0.79(0.44-1.01)$ in non-hypotensive group $(P=0.03)($ table 2$)$.

AUC of IJV area at supine are $0.75(0.54-0.93)$ and the cutoff value of IJV area was $1.35 \mathrm{~cm}^{2}$ (figure 1).

Table 1. Patient characteristics and baseline BP and HR

\begin{tabular}{|l|l|l|l|}
\hline \multicolumn{1}{|c|}{$\begin{array}{c}\text { Hypotensive } \\
\text { group }\end{array}$} & $\begin{array}{c}\text { Non-hypotensive } \\
\text { group }\end{array}$ & P value \\
\hline Age & $70.5(65-76)$ & $43.0(32-61)$ & 0.004 \\
\hline Sex (female) & 10 & 11 & 0.41 \\
\hline Systolic BP & $135(120-159.5)$ & $136(127-143.0)$ & 1 \\
\hline Diastolic BP & $72.5(64.8-83.5)$ & $79.0(73.0-90.0)$ & 0.1 \\
\hline Mean BP & $93(76-100.5)$ & $95(91-105.0)$ & 0.3 \\
\hline HR & $70.5(66-75)$ & $71.0(68-80)$ & 0.63
\end{tabular}

Figure 1. ROC curve

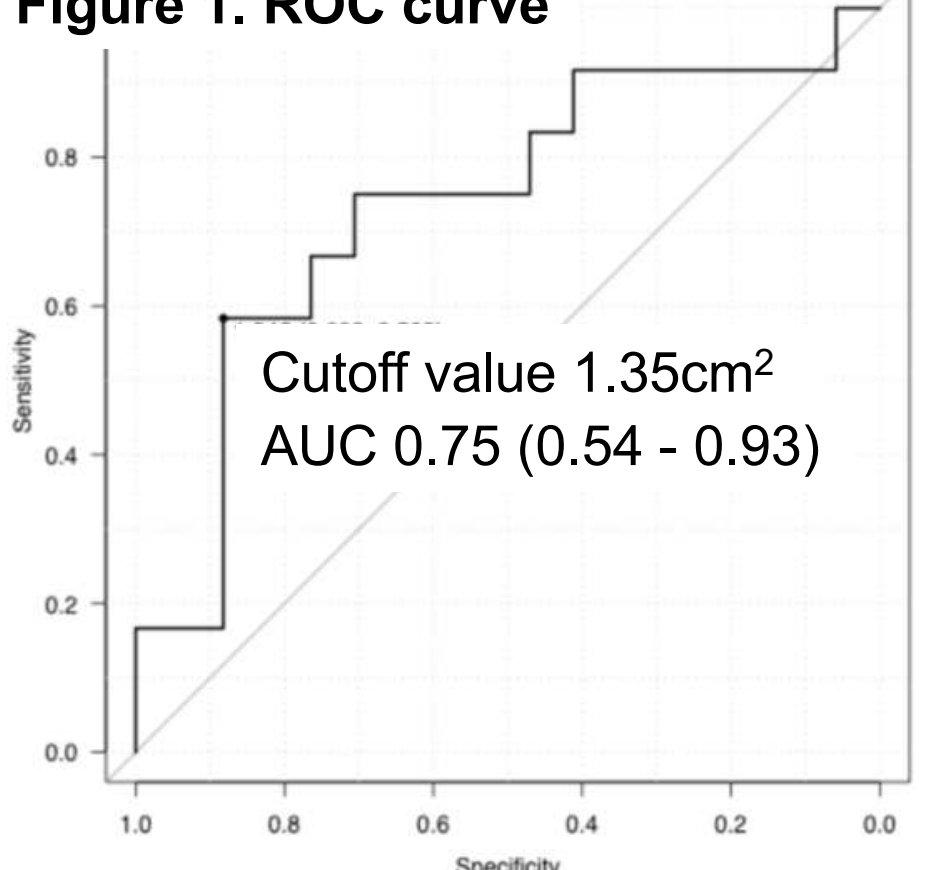
hypotension after induction.

Table 2. Ultrasonographic data

\begin{tabular}{|l|l|l|l|}
\hline & \multicolumn{1}{|c|}{$\begin{array}{c}\text { Hypotensive } \\
\text { group }\end{array}$} & $\begin{array}{c}\text { Non-hypotensive } \\
\text { group }\end{array}$ & P value \\
\hline IJV-D at Su $(\mathrm{cm})$ & $0.88(0.71-1.10)$ & $0.77(0.56-1.02)$ & 0.25 \\
\hline IJV-D at $\operatorname{Tr}(\mathrm{cm})$ & $1.22(1.00-1.29)$ & $1.14(1.08-1.19)$ & 0.38 \\
\hline IJV-D change rate $(\%)$ & $22(10-63)$ & $37(8-66)$ & 0.78 \\
\hline IJV-A at Su $\left(\mathrm{cm}^{2}\right)$ & $1.35(0.93-1.53)$ & $0.79(0.44-1.01)$ & 0.03 \\
\hline IJV-A at $\operatorname{Tr}\left(\mathrm{cm}^{2}\right)$ & $1.70(1.43-2.76)$ & $1.31(1.21-1.73)$ & 0.14 \\
\hline IJV-A change rate $(\%)$ & $34(16-83)$ & $52(16-149)$ & 0.33 \\
\hline
\end{tabular}

※ All data are represented as median \pm quartile.

\section{Discussion}

Contrary to previous reports of IVC, in our study, the larger IJV area was associated with the

- A possible explanation was that in the patient with larger IJV area, the higher sympathetic tone just before induction had shifted temporary large amount of blood to central vein. Therefore, it was suggested that after induction, BP had fallen greater as a result of sudden decrease in sympathetic tone.

> The other possible explanation was that larger IJV area had resulted of diastolic dysfunction. Due to diastolic dysfunction, BP after induction had markedly decreased.

$>$ Patients in hypotensive group were older than these in non-hypotensive group. There was no correlation between age and IJV area at supine. For further analysis, it is necessary to increase the number of cases and to perform logistic regression analysis.

> The IJV area at supine had a negative correlation with hypotension during the induction of general anesthesia. 